\title{
Forma y fondo: una etnografia de la materialidad de la justicia en Cali ${ }^{1}$
}

\section{Claudia Jimena Abello Castiblanco ${ }^{2}$}

Universidad Vrije Amsterdam, Países Bajos

claudiaj.abello@gmail.com

Recibido: 22 de julio de 2015

Aprobado: 11 de noviembre de 2015

Disponible en línea: 9 de mayo de 2016

\footnotetext{
1 Artículo de investigación, producto de la investigación realizada en el año 2013 como parte de la tesis de pregrado de antropología "Circulando por la rama: una etnografia sobre un juzgado civil en Cali”. Agradezco a la Universidad Icesi que financió parte de la búsqueda bibliográfica de esta investigación con el proyecto del centro CIES titulado "Estado de la cuestión sobre prácticas judiciales"

2 Antropóloga Cum Laude de la Universidad Icesi, Cali, Colombia
} 


\title{
Forma y fondo: una etnografia de la materialidad de la justicia en Cali Resumen
}

El artículo busca reflexionar acerca de la burocracia judicial desde una mirada centrada en la interacción entre las personas y las cosas. En otras palabras, se desea aportar en la comprensión de la configuración del Estado desde los múltiples vínculos entre objetos (los expedientes) y la gente (funcionarios y ciudadanos). Para ello el artículo está dividido en tres partes. En la primera se hace un balance bibliográfico de la forma como se han investigado los juzgados y los expedientes dentro y fuera del país. Seguidamente, está la descripción etnográfica del despacho explicando los cargos y funciones de los empleados y el ciclo que cumplen los expedientes en su interior. Finalmente se hace una reflexión teórica acerca de la materialidad de la justicia a partir de los datos etnográficos.

Palabras claves: materialidad; expedientes; etnografia de juzgados

\section{Form and Backdrop: An Ethnography of the Materiality of Justice in Cali}

\begin{abstract}
This article aims to reflect on the judicial bureaucracy from a point of view focused on the interaction between people and objects. In other words, we aim to contribute to the understanding of the configuration of the State from the different links between objects (files) and people (officers and citizens). For this purpose, the article is divided in three sections. The first section makes a bibliographical balance of the way (form) in which how courts and files have been researched in and outside the country. Then we have the ethnographic description of the office, explaining the positions and functions of the employees, and the cycle that files go through in them. Finally, we carry out a theoretical reflection on the materiality of justice based on ethnographical data.
\end{abstract}

Keywords: materiality; files; court ethnography

\section{Forma e fundo: etnografia da materialidade da justiça em Cali}

\section{Resumo}

$\mathrm{O}$ artigo visa refletir sobre a burocracia judicial desde um olhar centrado na interação entre as pessoas e as coisas. Em outras palavras, deseja-se contribuir na compreensão da configuração do Estado desde os múltiplos vinculos entre objetos (os expedientes) e pessoas (funcionários e cidadãos). Para isso, o artigo é dividido em três partes. Na primeira faz-se balanço bibliográfico da forma como tem se pesquisado os juizados e os expedientes dentro e fora do país. Seguidamente, está a descrição etnográfica do escritório explicando os cargos e funções dos empregados e o ciclo que cumprem os expedientes no seu interior. Por fim se faz reflexão teórica acerca da materialidade da justiça a partir dos dados etnográficos.

Palavras-chave: materialidade; expedientes; etnografia de juizados 


\section{Una mirada teórica a los juzgados y sus expedientes}

Un juzgado civil, como en el que yo realicé mi investigación, es un lugar donde las personas resuelven sus conflictos por medio del aparato judicial. El adjetivo civil se refiere a que solo se resuelven conflictos entre particulares surgidos por contratos, títulos o bienes, entre otros. Por otro lado, el calificativo circuito indica que recibe casos en el que se disputa entre 90 y 140 salarios mínimos, o procesos que por su naturaleza son asignados por la ley a ese tipo de juzgados.

En esta clase de despachos las personas que desean resolver el conflicto están representadas por abogados que traducen la vida cotidiana al lenguaje jurídico. Allí, el juez es el responsable de decidir los casos según sus herramientas legales, la información y las pruebas que aporten las partes. Pero en realidad ese trabajo no es realizado por un solo funcionario, sino por una red de personas que se encargan de desarrollar pequeñas tareas para llegar a la decisión judicial. De la misma manera, un juez y su juzgado hacen parte de un entramado mucho más grande que funciona bajo unas lógicas preexistentes estableciendo las jerarquias y las funciones de todas las instituciones estatales.

Al interior de los juzgados podemos encontrar carpetas llenas de documentos que se llaman expedientes. En ellos se guarda registro de las actuaciones que llevan a cabo los diferentes actores del proceso como: los abogados, el juez, los funcionarios y demás instituciones de la rama judicial. La vida del expediente inicia con la presentación de una demanda pasando por diferentes etapas para llegar a la sentencia. Aun así, el resultado final nunca está terminado, porque un tribunal superior siempre tendrá la posibilidad de reabrir el caso y hacer que el proceso continúe.

El campo de los juzgados y los expedientes en Colombia se ha explorado desde dos perspectivas principales. La primera la comprenden estudios que procuran entender la 'congestión' como un fenómeno propio del funcionamiento de la rama judicial (Arbeláez 1999; Uprimny, Rodríguez y García 2003; Ospina 2006; Calderón 2007; Moreno y Agapito 2009). 
En la mayoría de estos análisis se intenta caracterizar, con metodologías estadísticas o análisis normativos, las razones por las cuales los juzgados en Colombia son 'lentos', 'morosos' o 'paquidérmicos'. Estas visiones solo se concentran en mostrar la baja eficiencia de los juzgados y las maneras 'correctas' en las que debería funcionar la justicia en Colombia. En mí investigación indagué en cambio, por el día a día de un juzgado, concentrándome en los detalles que hacen al sistema tal y como es y en las categorias que usan las personas al interior del juzgado para referirse al funcionamiento de la justicia.

Un segundo grupo de estudios aborda los juzgados desde la 'praxis profesional' de los abogados y los jueces. Por medio de estas investigaciones se indaga por las prácticas y las concepciones de justicia que tienen los abogados litigantes y los funcionarios del poder judicial (Lynch, 1981; Silva 2001; Olano, 2004; García 2010). Este tipo de estudio investiga la manera en la que variables como el género (Bonelli, 2013; Mack y Anleu, 2012) o la edad (Boyea, 2010) afectan las maneras de hacer derecho. Utilizando la entrevista como principal metodología, se ilustra la 'cultura jurídica' en Colombia. En contraposición a este tipo de investigaciones centradas en el discurso, en este trabajo me enfoqué en la experiencia diaria del juzgado y no en lo que los abogados dicen que hacen, ya que esta perspectiva ha sido menos explorada en el país.

Por otro lado, el método etnográfico ha sido utilizado por autores extranjeros que describen ampliamente el funcionamiento de las altas Cortes. Uno de los autores es Bruno Latour (2010) que en su libro The Making of Law: An Ethnography of the Conseil d'Etat, lanza una mirada antropológica sobre el Consejo de Estado en Francia. Por medio de la teoría del actor-red, el autor explora el espacio, los expedientes y las personas que circulan en esa organización. Latour hace un seguimiento minucioso de los expedientes desde el momento que son recibidos por correo hasta la sentencia. En la perspectiva Latouriana, el expediente pasa por un proceso que lo hace madurar como un 'fruto' (Latour, 2010, p. 82) gracias a la agregación de información hecha por las partes del proceso. 
Otra autora que es de interés es Leticia Barrera (2012) con su libro La corte suprema en escena: una etnografia del mundo judicial. Barrera realiza una etnografia de la Corte Suprema de Argentina basándose en cuatro dispositivos: el lugar, los documentos, los sujetos y el performance. Barrera dice alejarse de los dualismos convencionales entre lo teórico y lo empírico, lo normativo y lo descriptivo, el texto y el contexto, abordando "la practica judicial como una técnica de producción del derecho capaz de modelarlo, de darle forma" (Barrera, 2012 , p. 32). Retomando los presupuestos metodológicos de estos dos autores me sumergi en la cotidianidad del mundo judicial, comprendiendo el funcionamiento de la Rama Judicial desde adentro. Sin embargo a diferencia de ellos, no me enfoqué en el trabajo de las Altas Cortes sino en un juzgado de menor jerarquía.

Debido a que selecciono una metodología etnográfica como la de los actores antes mencionados, la realización de esta investigación implicó una inmersión completa en la vida laboral del juzgado durante los meses de junio y julio del 2013. El objetivo de esta inmersión fue aprender las labores rutinarias de la fabricación de los documentos judiciales y entrar en el día a día de la vida del juzgado. Como parte de la inmersión en el juzgado caractericé el espacio de la oficina describiendo cuidadosamente las funciones que realizan cada una de las personas que trabajan en el lugar. También formé un inventario detallado de algunos de los expedientes a los que le hice un seguimiento describiendo su antigüedad, número de hojas, tipo de proceso, personas involucradas, etapa en la que se encontraba, lugar donde se ubica y espacios por los que circula. Por medio de la observación y la activa participación en las dinámicas rutinarias del despacho, comprendí íntimamente la experiencia afectiva de los trabajadores del juzgado. Con esta misma técnica exploré la manera en que las biografias de los expedientes se conectan con las biografias de las personas.

Como parte de la metodología etnográfica, esta investigación plantea que es posible introducirse en la cotidianidad del juzgado mediante la descripción de la producción y circulación de expedientes. Para algunos autores, los expedientes son una experiencia previa al derecho 
como una herramienta de acceso al conocimiento (cfr. Vismann 2008), es decir, "un mediador entre la norma y la toma de decisiones" (Barrera, 2012, p. 86). Así, existe una distinción tajante entre el proceso de formación del expediente y la sentencia final. Mientras que el primero es un vehículo de información que transita en un intercambio textual, la sentencia es una decisión final fundada en derecho. Desde esta perspectiva los expedientes y las sentencias son dos etapas completamente separadas, donde el expediente no hace parte de la formación del conocimiento jurídico ni de la toma de decisiones. En contraposición, el antropólogo norteamericano Mathew Hull afirma que los documentos burocráticos (Papeles de propiedad de las instituciones de Estado tal como los expedientes) "[ ...] no son meros instrumentos de las organizaciones burocráticas, sino constitutivos de la reglas, ideologías, conocimientos, practicas, subjetividades, objetos, resultados, e incluso de las organizaciones mismas" (Hull, 2012a, p. 253). Desde el enfoque de la materialidad que explora Hull, el discurso que contienen los documentos no puede ser abstraído del vehículo material en el que viaja. En mi investigación retomo esta última propuesta restringiéndola a los expedientes judiciales.

La bibliografia existente sobre el encuentro entre los documentos y las personas ha sido clasificada por Hull (2012a) en tres acercamientos que a veces se separan y otras veces se combinan: la estética, el afecto y los signos. En la primera perspectiva se explora cómo los usuarios responden a los patrones plasmados en los documentos haciendo énfasis en los elementos gráficos (párrafos, tablas, subtítulos, fuentes, márgenes y viñetas). En la segunda, varios investigadores describen el encuentro con los documentos en términos de afecto (affect). Según este tipo de autores, en la interrelación entre los documentos legales y las personas se desarrolla una 'energía afectiva' que carga los objetos con significados y sentidos (Navarro-Yashin, 2007) o de una agencia (Gell, 1998, en Telley, Webb, Küchiler, Rowlands y Spyer, 2006). El ultimo planteamiento ahonda en la forma en que los documentos conectan a las personas, lugares, cosas, tiempos, normas y formas de sociabilidad. Centrados en la denotación y los signos, dichos autores encuentran la unión entre el fondo y la forma. 
Es importante señalar que además de Hull existen otros autores cuyas perspectivas es necesario conocer para comprender la relación que pueden tener las personas y las cosas desde el enfoque de la materialidad. Siguiendo las ideas de Telley y colaboradores (2006), este campo de estudio parte de la idea de que lo material es una dimensión integral de la cultura necesaria para entender la existencia social.

Dentro de este marco, es de utilidad el concepto de biografia social de las cosas, propuesto por Kopittoff (1991 pp. 92-94). Para este autor las cosas al igual que las personas tienen una biografia que da cuenta del modo en que los objetos y las personas cambian de significado de acuerdo a los contextos por los que circulan. Por lo tanto es necesario seguir las rutas de circulación de los objetos para entender su inmensa maleabilidad en la que interviene también la agencia humana. En ese sentido, la noción de biografía cultural fue pertinente para entender los expedientes de una manera procesual y no como una cosa acabada. Relatar el origen, la circulación y producción de una cosa nos devela los juicios, convicciones y valores que moldean nuestra actitud hacia los objetos y sus cambios. Asociado a esta perspectiva procesual, el concepto de expediente de Barrera (2012, p. 42) me ayudó a comprender los expedientes como objetos que producen conocimiento, organizan conductas y crean rutinas. Siguiendo a esta autora, es por medio de la circulación de expedientes en la Corte Argentina que se crean, disputan, validan y difunden los conocimientos (Barrera 2011, p. 69). Es por esto que los expedientes no son meros instrumentos de comunicación sino agentes que afectan el mundo humano.

\section{Los funcionarios y sus cargos}

En un juzgado civil del circuito hay siete cargos establecidos por ley, cada uno de ellos con funciones específicas que pueden ser modificadas por las coyunturas que ocurren día a día en el despacho. El cargo más alto es el del juez, ocupado por Guillermo Cortés, quien es responsable de todo lo que pasa en el juzgado. No solo es el encargado de velar por que todos hagan su trabajo, siendo el jefe y la máxima autoridad, 
sino que responde ante procesos disciplinarios por cualquier error cometido por los funcionarios.

La persona que sigue en jerarquía es la secretaria, Dalia Flórez, quien realiza muchas tareas que en el juzgado se denominan 'administrativas'. Los secretarios deben ser abogados de profesión y requieren de un conocimiento extenso del procedimiento que deben seguir los expedientes. Sobre este cargo recaen funciones como: repartir los expedientes a las personas que corresponden, hacer las estadísticas del funcionamiento del juzgado para enviar al Consejo Superior de la Judicatura (CSJ) ${ }^{3}$, firmar documentos necesarios para los abogados como: títulos, permisos de embargo o autorizaciones de notificación. También resuelve cosas 'de fondo', es decir, casos o problemas jurídicos como: excepciones previas, tutelas difíciles y bocetos de sentencias.

El siguiente cargo es el de oficial mayor, puesto ocupado por Elisabeth Mondragón. Esta funcionaria es la que se encarga de resolver los casos más complicados evaluando las pretensiones ${ }^{4}$ de los abogados, las normas y las pruebas para 'proyectar' una decisión. La palabra proyectar indica un proceso en el que el funcionario hace un boceto del documento, que luego aprueba y firma el juez. En el mismo nivel que Elisabeth se encuentra Antonio. Él, más que resolver procesos en el área civil, se encarga de decidir sobre las tutelas. Debido a que las tutelas solo tienen diez dias hábiles para dictar sentencia, Antonio trabaja de manera ardua y constante en casos que exigen rápida solución.

El cargo que sigue es el de escribiente, que lo ocupan Carolina y Conchita, para este cargo no es necesario ser abogado. Ellas son las encargadas 'de sacar volumen', en otras palabras resuelven cosas sencillas de procedimiento que tienen plantillas predeterminadas, también transcriben las audiencias y los testimonios. La última en la jerarquía es Jazmín que ocupa el puesto de asistente judicial. A ella se le asignan los trabajos enteramente administrativos como: organizar

El Concejo Superior de la Judicatura es una institución creada a partir de la constitución de 1991, que se encarga de la administración de justicia y los procesos disciplinarios de abogados y funcionarios de la rama judicial.

4 Pretensiones se le llama a una parte estructural de la demanda en la que el abogado expresa lo que desea del demandado. 
los procesos que llegan, enviar telegramas y visitar los juzgados donde se debe enviar un expediente o un documento, archivar los expedientes, enviar las tutelas a la Corte Constitucional e ir al correo.

Finalmente estaba yo que ocupaba un puesto que no estaba definido, ni por la ley ni por nadie. Yo hacía muchas cosas, como ayudar a atender al público, organizar y encontrar los expedientes, ordenar los archivos y acompañar a Jazmín a entregar los papeles. Yo no tenía ni una función fija, ni tampoco escritorio. Revoloteaba por toda la oficina y los demás empleados me ponían a hacer diferentes cosas, de acuerdo con sus necesidades. Yo era una integrante extra, básicamente hacia lo que nadie quería hacer, o las tareas administrativas que ellos habian dejado de lado.

\section{Expedientes existentes}

La justicia glamurosa de estrados en madera y pelucas blancas dista de la realidad de los juzgados caleños. En el 2008 una bomba en el Palacio de Justicia trajo consigo un cambio fundamental en la rama judicial. Los juzgados fueron redistribuidos en la parte central de la ciudad. Algunos contaron con la suerte de obtener oficinas, mientras que otros terminaron en patios, cocinas, balcones, salas y habitaciones. Desde hace cinco años, muchos funcionarios de la rama experimentan la incómoda realidad de estar separados por kilómetros los unos de otros (ver figura 1). Digo incómodo porque cada juzgado está conectado a los demás, hay un flujo constante de expedientes y papeles entre los despachos, lo que significa que cientos de kilos de papel se trasportan en carritos, brazos, buses y taxis de empleados públicos que hacen circular el papel.

En el caso de mi investigación, un edificio en el barrio Versalles como cualquier otro hace las veces de juzgado, allí se albergan ocho de los quince despachos civiles del circuito en la ciudad. En el quinto piso se encuentra el despacho del juez Cortés, es uno de los más grandes que conocí de los juzgados que visité, a pesar de su pequeña área. Está compuesto por tres oficinas separadas por un corredor (ver figura 2). 


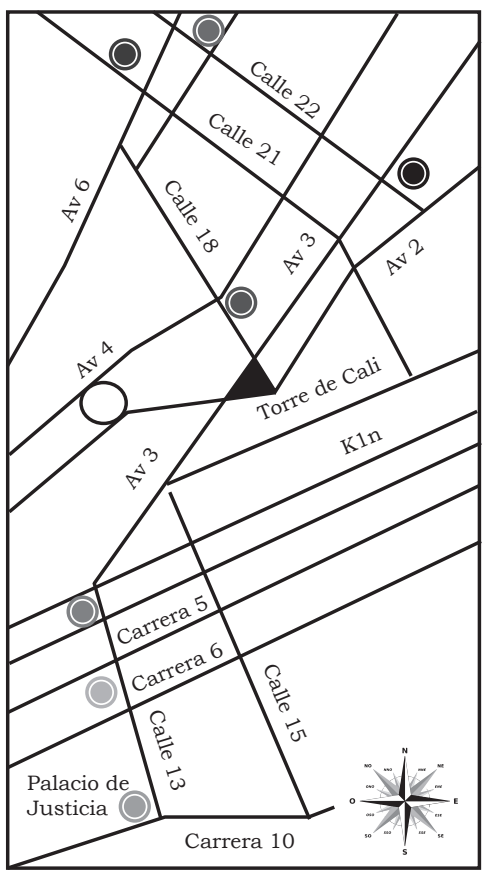

Edificio America: juzgados civiles circuito del 1 al 8: Av 3 con 22

Edificio Bambu: juzgados civiles circuito del 8 al 15: Av 5BN con 22 esquina

Edificio Bellini: juzgados municipales 2-5, 7-10, $12-15,17-20,22-25,27-30$ y $32-35$ : Calle $21 \mathrm{~N}$ No 6 an $-49 / 55$

Edificio Agualimpia: juzgados municipales $1,6,11,16,21,26,31$ : Calle 18N 3N-44

Tribunal: plaza de Caicedo

Administración judicial: centro comercial Plaza de Caicedo calle 12 - 5

Palacio de Justicia

Figura 1. Mapa de la ubicación de los juzgados civiles en Cali Fuente: Miguel Alfonso Velandia

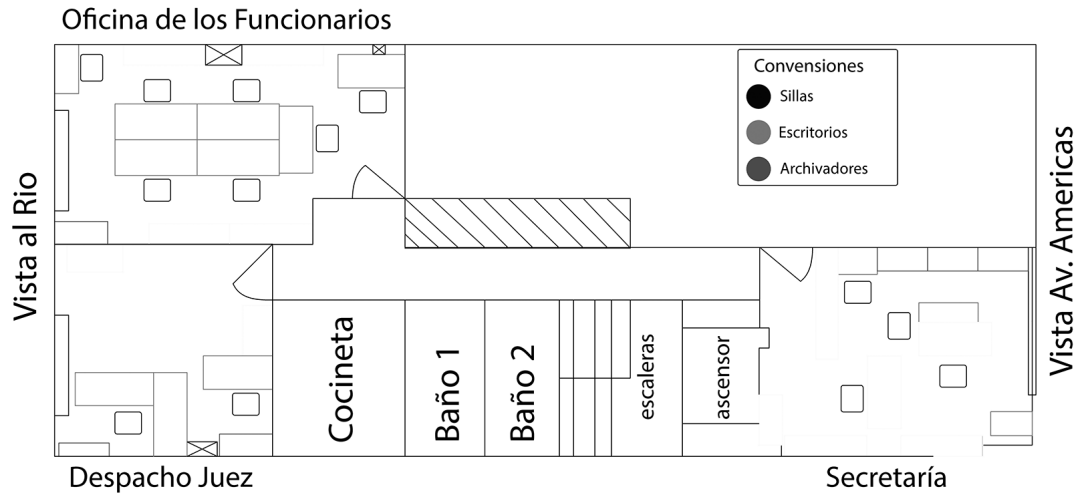

Figura 2. Mapa de la oficina completa del juez Cortés

Fuente: elaboración propia. Diseño: Miguel Alfonso Velandia 
En la primera oficina cerca del ascensor que llamaré la secretaría, se encuentran Dalia la secretaria y Jazmín la asistente judicial. Junto a ellas conviven más de mil expedientes, algunos de ellos reposan largo tiempo en las repisas, porque los abogados los han dejado quietos, le dicen la letra. De esos mil, otros están envueltos por cintas azules esperando a ser archivados. Otros están frescos como el pan caliente, recién trabajados por los funcionarios, a esta etapa le llaman estados. Si el juzgado fuera una panadería y los papeles que elaboran los funcionarios judiciales el pan, diríamos que la hogaza dura en el mostrador cuatro días. En ese lapso de tiempo los abogados pueden revisar el expediente haciendo copias, poniendo quejas y elaborando correcciones. Después del cuarto día el expediente pasa a reparto o ejecutoria, es decir, que espera a ser distribuido por Dalia a los demás funcionarios para seguir el proceso que tiene cada expediente, dependiendo de sus características.

El trabajo de los funcionarios judiciales consta siempre de las mismas tareas, pero eso no significa que todos los días hagan lo mismo. Jazmin por ejemplo es la encargada de hacer las notificaciones, en otras palabras, ella informa a los demandados que existe un proceso en su contra y deben presentarse en el juzgado. También es quien envía todo tipo de correspondencia a los entes del Estado relacionados con los expedientes. Su trabajo aunque mecánico, requiere de tiempo para llenar los formatos y mucha concentración para no cometer ningún error.

Dalia, por el otro lado, es la mente maestra detrás de toda la circulación, ella distribuye el trabajo para todo los del juzgado, de acuerdo a las funciones de cada quien. En el despacho cada funcionario tiene un número excepto el juez, eso permite saber quien ha trabajado los expedientes sin utilizar nombres propios. Dalia toma cada uno de los grupos de papeles y los mira detenidamente hasta saber el paso siguiente, escribe el número del funcionario correspondiente y una pequeña 'pista de lo que se debe hacer'.

La secretaria desfila en sus tacones por el largo pasillo que separa las tres habitaciones, en sus manos carga los pesados expedientes hacia la oficina de los funcionarios, situada al lado de la habitación 
del juez. Las dos escribientes, Carolina y Conchita, son quienes manejan el mayor volumen de papel en el juzgado. Esto se debe a que su relación con los casos es puntual, ellas deben redactar papeles cortos que ya tienen formatos establecidos, en los que indican a los abogados decisiones que influyen en el procedimiento y no en el caso concreto. La experiencia da la rapidez en este tipo de trabajo. Conchita es la más eficaz, hace doce años ocupa el mismo puesto, en cambio Carolina todavía se tarda en redactar los documentos, solo llevaba seis meses en su cargo actual.

Mientras tanto al otro lado de la oficina, Elisabeth y Antonio no deciden sobre el procedimiento sino sobre el fondo. Ellos redactan escritos más largos y complejos que enlazan las peticiones de los abogados, la ley y la decisión del juez. A este acto se le llama proyectar una decisión o sustanciar. Ellos miran con atención los expedientes, los leen, los analizan, los marcan, los copian y pasan con un expediente el día entero; todo para entender y justificar la decisión del juez.

La oficina de los funcionarios es estrecha y en ella hay menos expedientes. En el escritorio y la estantería de cada funcionario judicial descansan aquellos procesos que 'están para ser trabajados', expresión que se utiliza con frecuencia para que los abogados se calmen y sepan que en unas cuantas semanas su petición será atendida. A continuación un fragmento del diario de campo que refleja cómo se usa esta palabra.

Una abogada muy blanca, de voz prepotente, me preguntó por unos expedientes. Yo le di la información que estaba en el sistema, estaban repartidos para trabajar, y le pregunté a la 'doctora': ¿Qué necesita del proceso doctora? A lo que respondió, pues eso, que lo trabajen.

Los espacios adicionales a los estantes y escritorios de los funcionarios como las sillas, el suelo y los escritorios extra, se encuentran invadidos con frecuencia por torres de expedientes, que cada funcionario organiza, conforme los expedientes circulan. 
Cuando los papeles están listos, son arrumados en un quinto escritorio en el que Dalia revisa el trabajo hecho, vigilando que todo esté en orden para la firma del juez. Este último funcionario se comporta como el gran ojo que vigila: él no escribe todas las sentencias pero supervisa que estas expresen su opinión. Él no escribe los papeles donde se deciden asuntos de procedimiento, pero confia en el visto bueno de la secretaria. El juez firma como símbolo de su aprobación, pasando los expedientes a la persona que debe escribir las carteleras que indican los estados ${ }^{5}$, cada día es un funcionario diferente. Luego, alguno de los funcionarios judiciales desfila hacia la secretaria, para llevar el trabajo del día a los estantes de exhibición (Ver figura 3).

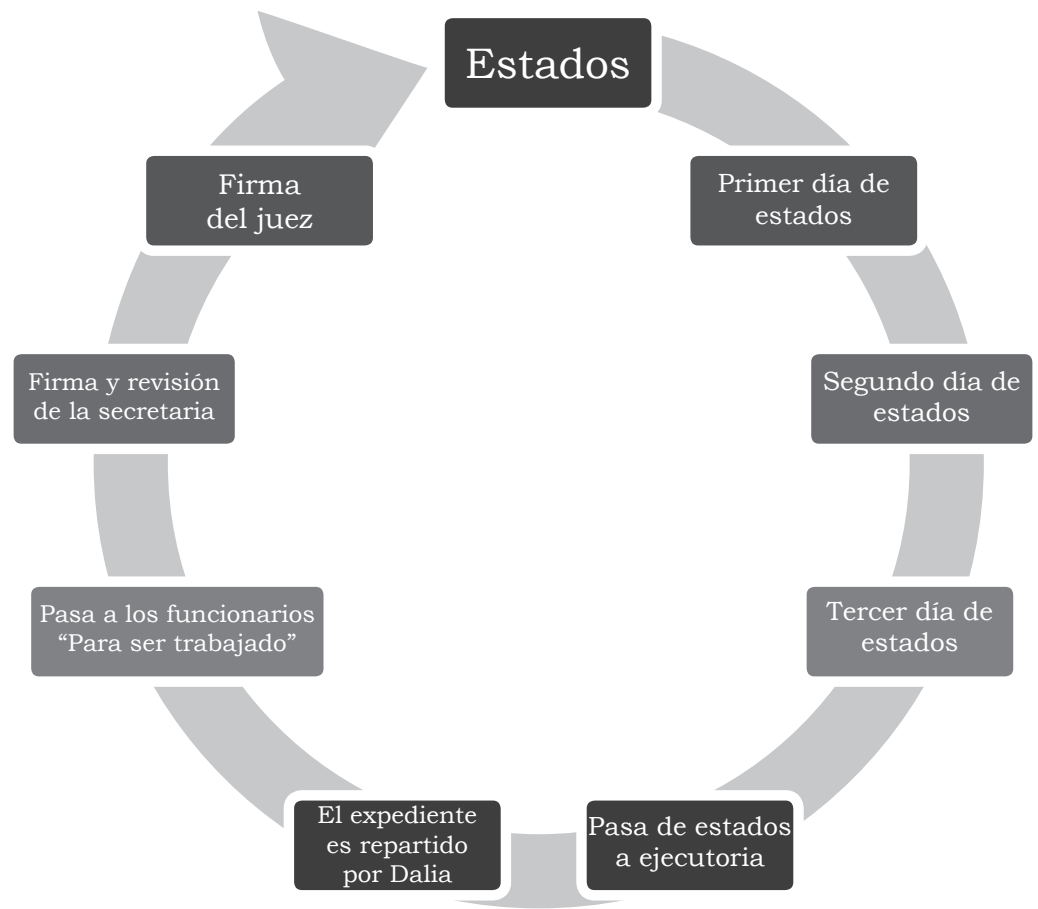

Figura 3. La circulación de los expedientes civiles existentes

Fuente: elaboración propia

5 Los estados son una forma de notificación a las partes, de los nuevos documentos que produjo el despacho. Los expedientes duran en estados cuatro días (Estados, primer día, segundo dia y tercer dia). 


\section{Expedientes nuevos}

El ir y venir de los expedientes está influenciado por personas externas al juzgado, que llevan y traen el papel de otras oficinas. Iniciaré con el caso de William, quien trae desde la oficina de reparto las carpetas que en el transcurso de un par días se convertirán en expedientes. Este funcionario no hace parte directamente del juzgado pero es el encargado por el CSJ, de repartir los procesos a los despachos civiles. Él llega en un vehículo del Estado desde el centro comercial Plaza de Caicedo, el sitio de acopio y distribución de carpetas y expedientes. Las carpetas son la colección de papeles que se recogen en administración judicial, provienen de abogados o personas que ponen sus procesos a disposición de la rama judicial. Aunque los expedientes son también carpetas, ellas están cargadas de formalismos, como las caratulas de la rama judicial, que los hacen un documento oficial.

Cada mañana Dalia acepta las carpetas, firmando un formato de recibido y vigilando que cumplan los requisitos minimos de jurisdicción y competencia. En otras palabras, ella revisa que se practiquen las exigencias de ley, para que luego no haya faltas en el procedimiento que anulen el proceso. William también está encargado de recoger los títulos judiciales, que son formatos que les permiten a los abogados recoger dineros que se encuentran en las arcas de la rama judicial. El recorrido de William abarca gran parte de la ciudad, no se queda largo tiempo en la oficina, hay muchos papeles que repartir.

De las manos de la secretaria, las carpetas pasan a Jazmin, que es la encargada de convertir las carpetas en expedientes. Lo primero que ella hace es anotar la información de la carpeta en el libro radicador. Aunque existe un software que le ayuda a los juzgados a almacenar la información y los movimientos de los expedientes, se siguen manejando registros físicos de los actos a través de los libros de entrada y salida de los procesos. Seguidamente, ella toma una carpeta blanca donde marca de nuevo la información del proceso, acompañado de los veintitrés dígitos del número de radicación, que se utiliza en el sistema para dar la información de los casos. 
Luego de que los papeles son organizados al estilo que sugiere el juez, los nuevos expedientes esperan a ser repartidos por Dalia, quien designará a alguna de las dos escribientes para hacer la admisión de la demanda (ver figura 4). Aquí un fragmento del diario de campo que describe lo que hacían Dalia y Jazmín a la llegada de los nuevos expedientes.

Mientras Jazmin buscaba en qué le podía ayudar, vi como Dalia repartía los procesos. Después de que pasan por las manos de Jazmín que los ingresa al sistema, los pone en carpetas y los 'folea', regresan donde Dalia que dependiendo del asunto los reparte y anota en una tabla en Excel.

Acopio de

carpetas por

administración judicial
William entrega

las carpetas a

Dalia y ella las acepta
Diana pasa

la carpeta a

Jazmin quien

la incerta en el sistema
Jazmí entrega

el folder oficial

a Dalia para

ser repartido a

las escribientes
Admición

de la

demanda

Figura 4. Proceso de circulación de los expedientes nuevos

Fuente: elaboración propia

\section{Las tutelas}

Las tutelas son procesos de una indole distinta a los que normalmente llegan a los juzgados civiles del circuito. Estos procesos son un instrumento de protección de los derechos fundamentales de las personas en territorio colombiano y pueden ser presentadas sin intermediación de un abogado. Ellas deben resolverse en un plazo de diez días hábiles si es una primera instancia, si hay una apelación entonces el juzgado de mayor jerarquía tendrá veinte dias hábiles. Todo lo que se expone en una tutela se presume verdadero si la parte contraria no lo desmiente. Algunas veces se le solicita a quienes presentan la tutela y 
representantes de las entidades, rendir indagatoria para obtener más datos que ayuden a resolver un caso concreto.

Las tutelas al igual que los expedientes llegan por medio de William y de la administración judicial. Antonio es el funcionario encargado principalmente, de proyectar este tipo de procesos. Existen dos diferencias fundamentales entre las tutelas y los casos civiles: primero, las pretensiones en los casos de derechos fundamentales son vagas y difusas a diferencia de los casos civiles en las que deben ser concretas. Por lo tanto, es necesario que el funcionario tenga la habilidad de comprender los contextos sociales desde donde la persona habla, ya que el lugar de enunciación sí importa en este tipo de casos. No como en los casos civiles donde el funcionario intenta ser imparcial, busca separarse de la situación social de cada parte. Segundo, los folders de las tutelas resultan ser más delgados porque tienen menor circulación por el juzgado al ser un proceso que solo dura diez días. En cambio los expedientes civiles son gruesos porque pasan mucho más tiempo en el despacho, algunos tienen hasta quince años, aumentando su grosor con los documentos que crean y van añadiendo funcionarios y abogados.

Algunas de las sentencias complicadas se las dejan a Dalia. En su mayoría son sentencias contra juzgados, es decir, cuando una persona denuncia que un juzgado ha violado alguno de sus derechos procesales, como el derecho a la defensa. Son casos difíciles en tanto requieren un amplio conocimiento de la norma procesal y sus principios. Además, este tipo de sentencias tienen un alto costo político, porque se juzga a un funcionario de la misma rama judicial que después puede convertirse en un superior. Otras tutelas de corte más sencillo y rutinario se las entregan a Jazmín.

El funcionario construye una sentencia basándose en modelos que ha realizado de procesos similares. A continuación, en un pedazo del diario de campo se describe la forma como Antonio analiza las tutelas. 
Él mira la tutela de atrás para delante, observando cual es el siguiente paso a conquistar. Abre un modelo de un caso parecido anterior y lo empieza a modificar cambiándole los datos y el caso concreto. Él afirma que las plantillas ayudan, pero que muchas veces debe cambiar casi todo.

Algunas veces las tutelas resultan tan complejas que Antonio va a la oficina del juez a que este le dé un criterio para erigir la sentencia. Dos días antes de cumplirse el plazo se imprimen los documentos y se envía una comunicación a las partes, por medio de la asistente judicial, notificando la sentencia. A partir de ese momento los expedientes de las tutelas descansan en el puesto de Jazmín, quien debe enviarlos a la Corte Constitucional en Bogotá, para su revisión.

Semanas después de ser enviadas, las tutelas regresan al juzgado envueltas en bolsas de plástico, por medio de las personas que entregan el correo. A partir de este momento los expedientes pueden tener dos destinos. En el primero, el expediente servirá como apoyo a otro proceso llamado desacato, en el que el juzgado toma medidas más estrictas contra la entidad para que se dé el cumplimiento de la sentencia. En el segundo, Jazmín empaca las tutelas con cintas azules para llevarlas al archivo (ver figura 5).
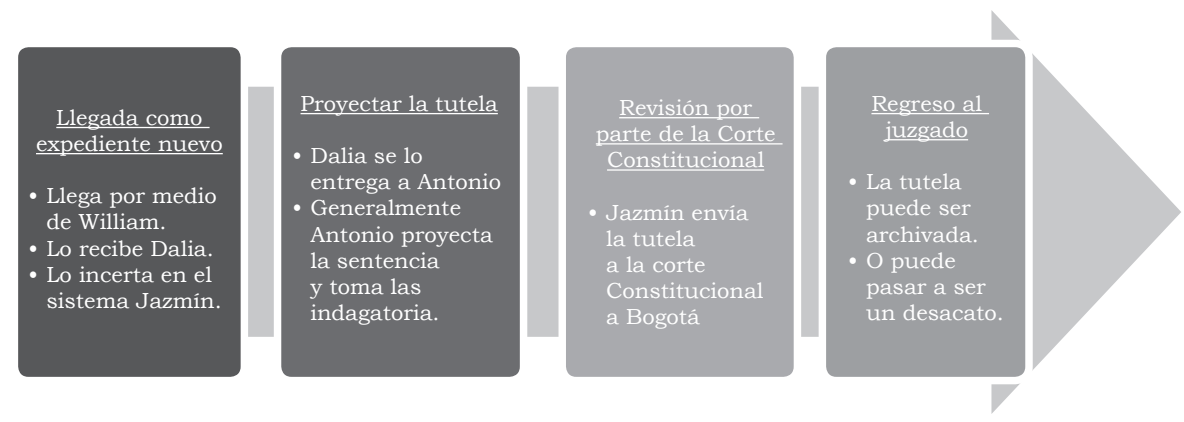

Figura 5. Circulación de las tutelas

Fuente: elaboración propia 


\section{Fuera del juzgado}

He pasado por el centro de Cali un millón de veces, un lugar bullicioso y concurrido. Un sitio donde se asientan las principales entidades del Estado, financieras y comerciales. A diferencia de los Down Town de las grandes metrópolis norteamericanas, el centro de la sucursal del cielo no tiene un encanto especial, el dinero fluye camuflado de pobreza, calor y hacinamiento. Después de mis dias de campo, el centro no fue más ese lugar desconocido que era antes. Gracias a Jazmín entré a edificios, caminé por la plazas, supe el nombre de las calles y donde se ubicaban los restaurantes cercanos. Con ella aprendí el quehacer de una asistente judicial.

Salir con Jazmín a caminar el centro era una de mis partes preferidas del trabajo de campo. Los recorridos iniciaban en Versalles, un barrio cada vez más comercial. De allí partíamos cargadas de papeles que serían repartidos. Nuestra labor era entregar expedientes y comunicaciones en otros lugares de la ciudad. La funcionaria conocía las rutas al dedillo, intentaba hacer recorridos circulares que le economizaran tiempo y energía. Ella también disfrutaba salir conmigo, porque entre las dos repartiamos el peso del papel y nos íbamos charlando todo el camino.

Frecuentemente visitábamos los juzgados civiles municipales de Bellini y Agua Buena, juzgados de menor jerarquía (ver figura 6). Como principio de la ley procesal los casos deben tener derecho, en su mayoría, a una doble instancia ${ }^{6}$. Por lo tanto, las partes que no estuvieran de acuerdo con una decisión del juez municipal podían presentar un recurso ${ }^{7}$, que le permite a un juez de mayor jerarquía revisar el juicio. En consecuencia la labor de Jazmín era comunicar a esos juzgados la decisión que tomaba el juez del circuito, devolviendo los expedientes y entregando escritos. Seguidamente un trozo del diario de campo en el que se describen los edificios de Bellini.

6 Doble instancia: "[...] el principio de doble instancia se construye con el fin de asegurar la posibilidad de corregir los errores en que pueda incurrir el juez u operador jurídico en la adopción de una decisión [...]. Sentencia C-718 del 2012 MP. Jorge Ignacio Pretelt.

7 Los recursos son 'herramientas' que permiten controvertir algunas decisiones judiciales por considerarlas que no se ajustan a derecho. (Tomado de presentación Procesal 2 , Andres Felipe Flórez). 
Bellini es un lugar etnográfico grandioso, es un edificio donde originalmente se ubicaban unos apartamentos realmente grandes, que convirtieron en juzgados. Algunos de los despachos fueron ubicados en antiguas habitaciones o salas, pero los más llamativos son los que se encuentran en las cocinas. Es gracioso ver las paredes de cerámica, las alacenas y los sifones todos cubiertos de expedientes. Las personas repartidas en un espacio inapropiado. Pero todo está tan naturalizado que la única que parece ver la cocina soy yo.

A comparación de Bellini, Agua Buena es una casa grande. En ese sitio se ubican los juzgados municipales terminados en 1 y 6 . Como en Bellini, algunos despachos terminaron en la habitación o la sala de la casa, a otros les tocó en los patios y lavaderos. Cada despacho es diferente, la posición de los muebles, las decoraciones y mejoras dependen de la forma de ser del juez. Recuerdo a una jueza que al llegarle el rumor de que en el remodelado Palacio de Justicia no podría tener otros electrodomésticos que los dotados por la rama judicial, se sentía triste e incómoda. Ella argumentaba que en su despacho tenía un televisor que le permitía ver novelas en las horas de descanso, otros jueces no se perdian un solo partido de la selección Colombia.

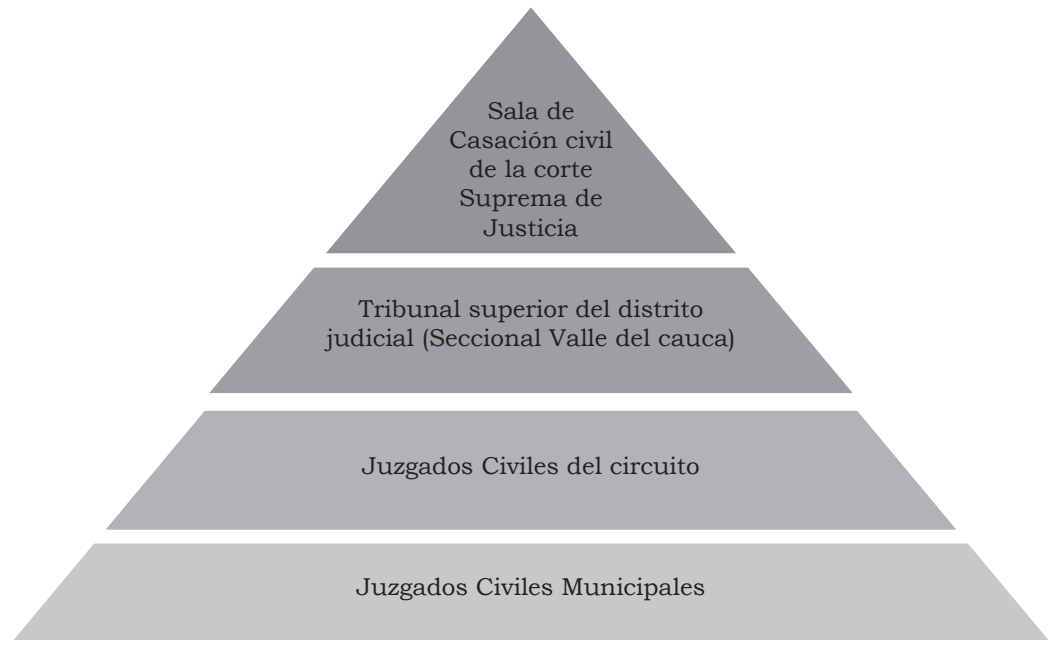

Figura 6. Jerarquía de los juzgados de Cali

Fuente: elaboración propia 
Otro edificio que visitábamos con frecuencia era el Palacio Nacional, sede del Tribunal Superior del distrito judicial del Valle del Cauca y el CSJ seccional Cali. De la misma manera como el juzgado del circuito revisa las decisiones de los juzgados municipales, el tribunal examina los juicios de los jueces del circuito. El tribunal funciona como un órgano colegiado que se divide en salas. En otras palabras, un magistrado ponente es el encargado de exponer el caso y su solución ante un grupo de jueces que pertenecen a la misma materia, ya sea civil, laboral, penal, familiar y otros. El grupo de jueces es quien decide acerca del caso por medio de la votación. Por otro lado el CSJ actúa como un ente administrativo y disciplinario de la rama judicial. En consecuencia, ellos deciden sobre la cantidad de juzgados, los materiales necesarios para su funcionamiento y el comportamiento adecuado de los funcionarios públicos y abogados, entre otras cosas.

El palacio es un edificio de cinco pisos terminado en 1933. Es una edificación con influencia europea y se erige como un copo blanco entre las palmeras de la Plaza de Caicedo, el centro del centro. El piso ajedrezado, los jardines que cuelgan de los balcones interiores y la amplitud de las oficinas, contrasta en mi mente con las cocinas de Bellini y los patios de Agua Buena. Gente joven camina por los pasillos, la mayoría estudiantes de derecho que realizan la Judicatura, una práctica gratuita en la rama judicial. Las personas de mayor edad son los magistrados que en su mayoría son hombres.

Jazmin entraba con frescura y entregaba los papeles, algunas veces subiamos hasta los despachos de los magistrados, cuando el juez necesitaba que las secretarias de su superior le dieran más plazo para entregar ciertos documentos. A la vuelta del Palacio se encontraba la administración judicial y reparto. Esas oficinas siempre estaban llenas de abogados, personas que venían a entregar las carpetas y de funcionarios que regresaban expedientes que no cumplian los requisitos de ley o tenían que ser repartidos para una segunda instancia. La última entidad que generalmente visitábamos era el correo. Allí Jazmín recogía los documentos que certificaban que el correo que ella enviaba desde la oficina había sido recibido. 


\section{Lo que no circula}

La copia auténtica es un oxímoron frecuentemente utilizado en el lenguaje jurídico, que expresa la complejidad del concepto de la prueba. Los papeles se guardan como muestra de la concreción de la acción en un objeto material. Algunos elementos que se guardan en el despacho son las copias de los autos, títulos, oficios y sentencias. Cuando Dalia lleva los papeles trabajados por los funcionarios a la oficina del juez, él firma dos documentos; uno que va permanecer en el expediente y otro que actúa como constancia. Ambos papeles son idénticos hasta ese momento, los dos cuentan con la misma información y una firma a lapicero negro ${ }^{8}$ del juez. Al llegar a la secretaría, Dalia revisa de nuevo que la información puesta en las carteleras del estado corresponda con los expedientes firmados por el juez, poniendo un sello con el día en que el proceso entra al anaquel. Mientras tanto la copia suelta es retirada del expediente y almacenada.

Del mismo modo, cuando se construyen las sentencias estas se imprimen dos veces, una pertenece al expediente y la otra es organizada en folders. El juez de mi despacho tiene almacenadas sus sentencias desde el 2009. Como es dificil y demorado encontrar los archivos, es mejor buscar la sentencia dentro de los archivadores, como ellos los llaman. Cada funcionario está encargado de almacenar documentos distintos y de mantener una estadística de su producción. También se almacenan todo tipo de recibos, confirmaciones, constancias y papeles que llevan registro de todas las acciones llevadas a cabo dentro del juzgado.

Otra forma de acumular es por medio del archivo, los expedientes no se pueden destruir, por lo tanto se almacenan. Cuando un caso se cierra y ya nadie cree que lo necesita, los expedientes son organizados en cajas y enviados a una bodega llamada Britilana, ubicada a treinta minutos del juzgado. Ese espacio oscuro, húmedo y frío es el destino casi final de un expediente. Digo casi porque es frecuente que los abogados soliciten desarchivar los procesos cuando necesitan alguna información. Esto le causa un gran dolor de cabeza a los funcionarios

\footnotetext{
8 En los documentos de la rama judicial nunca se utiliza otro color de bolígrafo que no sea negro.
} 
judiciales, en especial a Jazmín la encargada de organizar el archivo, que debe buscar en el mar de ácaros, procesos que ya estaban fuera de la oficina.

Por otro lado, el descuidado ambiente donde se almacenan los expedientes ha sufrido numerosos accidentes en el transcurso de la historia de la rama judicial caleña. Los funcionarios hablan de inundaciones y bombas que han destruido varios de los archivos. También es frecuente que los procesos estén perdidos, porque no existe ningún tipo de vigilancia al interior de Britilana, entonces, a pesar de los inventarios que el CSJ obliga hacer, nadie sabe a ciencia cierta cuántos ni cuáles procesos descansan en el archivo. Los únicos documentos que se encuentran en buen estado son los del fondo judicial, que ahora pertenecen al Archivo Histórico de Cali.

\section{Una mirada teórica a la circulación de expedientes}

Una herramienta útil para comprender la circulación de los expedientes es el de biografía social de las cosas propuesto por Kopittoff (1991, pp. 92-94). Para él las cosas, al igual que las personas, tienen una biografia que da cuenta del modo en que los objetos y las personas cambian de significado de acuerdo a los contextos por los que circulan. Los expedientes inician como la transformación de un problema de la vida diaria a un objeto material. De hechos, pruebas y argumentos orales a documentos en el papel. A continuación los papeles son procesados por la administración judicial, que con unos datos mínimos (tipo de proceso, cuantía, nombre de las partes) distribuye el trabajo entre los juzgados correspondientes. De allí pasa a manos de distintos funcionarios, en el juzgado, quienes agregan más documentos.

En concordancia con Kopitoff, hay que anotar que los expedientes tienen varias etapas, algunas de ley y otras que hacen parte del funcionamiento interno del juzgado. Más que narrar, lo que ya fue contado en las páginas anteriores, creo que los dos siguientes gráficos ilustran a manera de resumen, tanto lo que la ley exige como lo que sucede dentro del juzgado (ver figuras 7 y 8 ). 


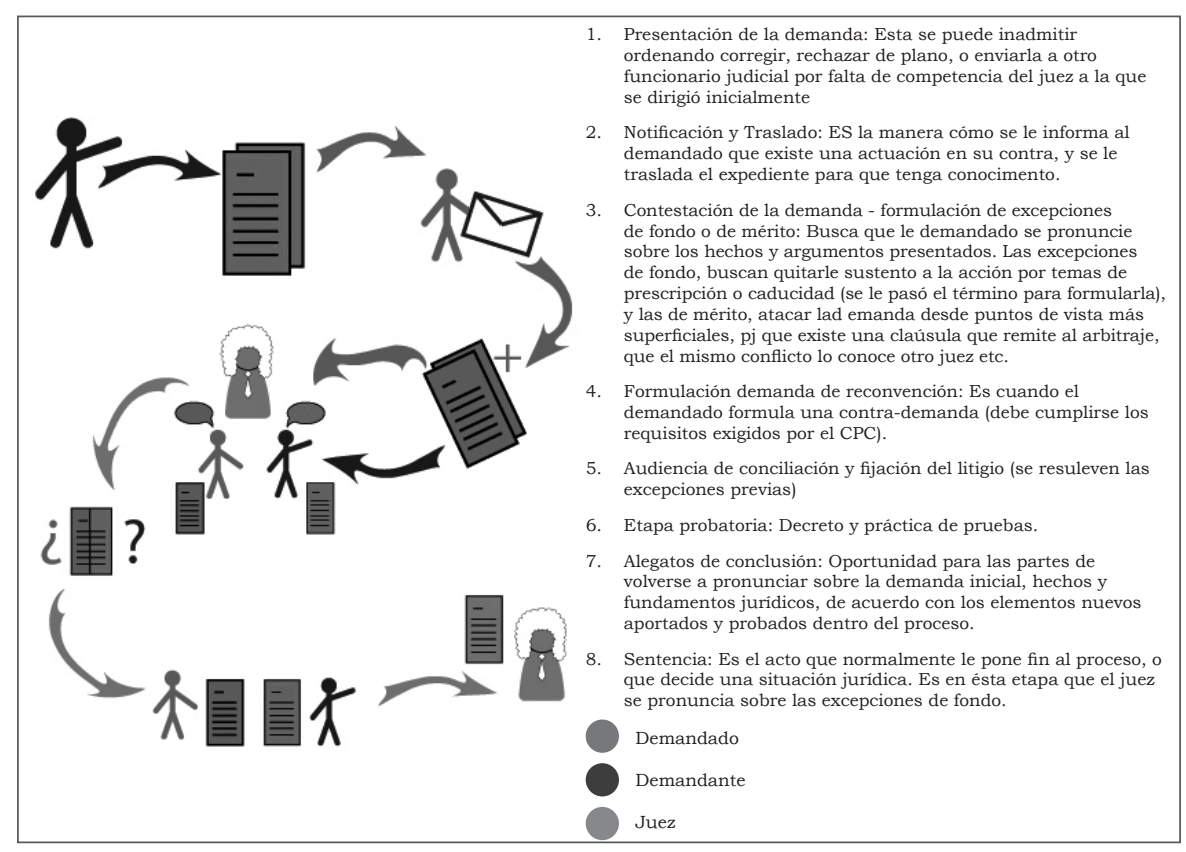

Figura 7. Imagen de las generalidades de un proceso civil según la Ley

Fuente: elaboración propia. Diseño: Miguel Alfonso Velandia

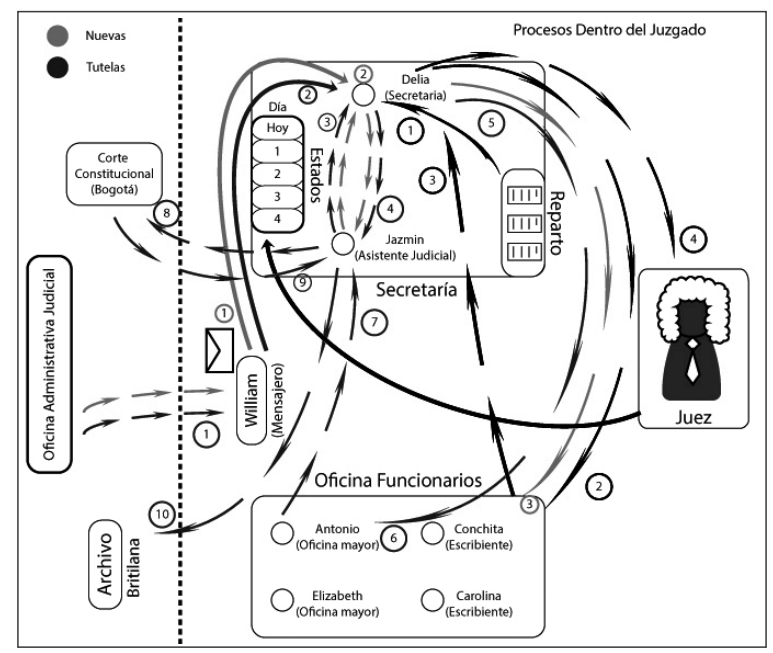

Figura 8. Resumen de la forma como circulan los expedientes en el juzgado dependiendo del tipo de proceso

Fuente: elaboración propia. Diseño: Miguel Alfonso Velandia 
En la breve descripción de los procesos, podemos comprender cómo para cada funcionario el expediente significa algo distinto. Según Mathew Hull a través del expediente, los funcionarios localizan sus acciones dentro de un presunto contexto alrededor de sus acciones (2003, p. 300). Por ejemplo, Dalia, Antonio y Elisabeth hacen análisis más extensos del expediente al tener que tomar decisiones que involucran grandes volúmenes de información. Ellos pueden pasar con un expediente el día entero, al tener que leerlos casi en su totalidad. Para solucionar un problema jurídico se debe tener compresión de las etapas del proceso, la ley, el contenido del expediente y las demandas de las partes. Mientras tanto, para otros funcionarios el expediente se comporta como un cadáver exquisito, en el que cada funcionario solo sabe un fragmento de la información. Las personas que ocupan cargos administrativos como los escribientes, asistentes judiciales, el correo, reparto, entre otros, no necesitan conocer el contenido completo del proceso para realizar la función correspondiente a su cargo. Así pues, el expediente se convierte en una brújula que ubica las tareas correspondientes a cada quien.

En el tránsito de los expedientes por los circuitos dentro y fuera del juzgado, se despliegan palabras que describen una forma de pensar lo que se hace con el expediente. La palabra proyectar, por ejemplo, imprime en el expediente un aire clarividente. Pues el funcionario es capaz de saber una decisión futura, como si a través del expediente pudiera esclarecer una verdad antes incierta. Si tenemos en cuenta que los procesos civiles son de tan larga duración, podremos entender que todo resulta ajeno para el funcionario que resuelve el caso concreto. Probablemente el Oficial Mayor no conoce a las partes, ni la travesía que el expediente ha dado para llegar a sus manos unos años después. En palabras de Gupta, "[El expediente] es un objeto material, pero alcanza una vida por sí misma que es frecuentemente más larga que la de las personas que actúan sobre él" (Gupta, 2012, p. 146. Traducción propia). El expediente le permite al funcionario develar un futuro, a partir de su contenido se construyen las decisiones judiciales.

A partir de la circulación del expediente también se construye la distinción entre lo procesal y lo sustancial, de la forma y del fondo. 
Mientras las primeras dos categorías (procesal y forma) designan trabajos rutinarios y de formatos ya establecidos; la segunda (sustancial y fondo), implica un conocimiento amplio de la ley en la que se entra a decidir sobre el caso concreto. Por ejemplo, si se inicia un proceso para el cobro de un pagaré, la escribiente que construye el documento de admisión de la demanda no entra a decidir sobre el derecho que tiene esta persona de cobrar o no el título valor ${ }^{9}$, sino que mira si el expediente cumple con todos los documentos expresamente enumerados por la ley para admitir la demanda.

Aunque se asume en la vida laboral que estos dos ejercicios son enteramente distintos, las líneas se desdibujan cuando llegan caso dificiles. La notificación por ejemplo es un requisito procesal en el que el juzgado y el demandante intentan avisar al demandado que existe un proceso en contra de él. Este formato lo realiza la asistente judicial, quien se encarga de materias de forma. Si no se notifica debidamente a una persona, no solo se incumple la ley procesal sino que se afecta un derecho fundamental de las personas, el derecho a la defensa, lo que puede causar que el proceso se anule. Si esto ocurre el abogado debe presentar una tutela en contra del juzgado, que será procesada por una persona como Dalia que se encarga de materias de fondo. Por lo tanto la forma y el fondo son dos caras de una misma moneda, no subsiste el uno sin el otro.

Las mismas palabras proceso y expediente demuestran una lógica del pensamiento de los funcionarios, para quienes coloquialmente hablando, es lo mismo un negocio, un proceso y un expediente. En la doctrina jurídica estas dos últimas palabras son distintas, mientras el primero es un conjunto de actos que aplican la ley general a un caso concreto para dirimirlo (Gómez 2000, p. 95), el segundo es un "conjunto de documentos correspondiente a un asunto o negocio" (Noticiero Oficial, 2013). En la vida cotidiana del juzgado como en la escritura de este capítulo, esta diferenciación no es tan relevante, porque cuando un funcionario o abogado hablaba de un proceso o negocio, se sabía que hablaba de un expediente.

9 Título valor es un documento escrito, firmado por dos partes que tiene un valor cambiario. Algunos ejemplos de títulos valores son: el cheque, el pagaré y la letra de cambio. 
La noción de biografia cultural es pertinente también para entender los expedientes de una manera procesual y no como una cosa acabada. A diferencia de otros objetos terminados como un libro, los expedientes son objetos que se encuentran en continua construcción. Cada expediente es un objeto único que tiene un mismo comienzo, una carpeta en la oficina de reparto, pero nunca el mismo trayecto. Cada expediente viaja acumulando documentos, sellos y firmas de acuerdo a las coyunturas que presenta cada caso. Mientras un proceso civil del UPAC ${ }^{10}$ puede llevar quince años circulando en el mismo juzgado, manifestando en su contenido el cambio de jueces, funcionarios y leyes; una tutela que se resuelve en diez días tiene un ciclo más breve. Por lo tanto concuerdo con Hull al afirmar que "el expediente es una crónica de su propia producción, una sedimentación de su propia historia" (2003, p. 296. Traducción propia).

En definitiva, el expediente es un objeto que no solo es producido sino un objeto que produce realidades en el mundo. Es un objeto que narra su propia historia y está en constante construcción. A través de su circulación, el expediente toma diferentes significados que demuestran una forma particular de pensar por medio de los objetos. Un pensamiento que se construye a través de una categoría binaria como forma y fondo; a través de una visión de futuro (proyectar) y de una concreción de lo abstracto en lo material (el proceso y el expediente).

\section{Referencias}

Arbeláez, L. (1999). Modelo de Gestión de los Juzgados de Itagüí: Una Alternativa de Solución para la Justicia Colombiana. En Fuentes, A. (Ed.), Reforma Judicial en América Latina. Una Tarea Inconclusa. Bogotá: Corporación Excelencia en la Justicia. Recuperado de http://www.oas.org/juridico/spanish/adjust16.htm

Barrera, L. (2011, septiembre). Más allá de los fines del derecho: expedientes, burocracia y conocimiento legal. Revista de Ciencias Sociales (41), 57-72.

${ }^{10}$ La unidad de poder adquisitivo constante (UPAC) era usada para calcular el costo de algunos de los créditos de vivienda. Para más información ver: http://www.banrep.gov.co/series-estadisticas / see_upac.htm 
Barrera, L. (2012). La corte suprema en escena: una etnografia del mundo judicial. Buenos Aires: Siglo XXI editores.

Bonelli, M. (2013). Gender and Difference Among Brazilian Lawyers and Judges: Public and Private Practice in the Global Periphery. Indiana Journal of Global Legal Studies, 20(2), 1291-1309.

Boyea, B. D. (2010). Does Seniority Matter? The Conditional Influence of State Methods of Judicial Retention. Social Science Quarterly, 91(1), 209-227.

Calderón, L. A. (2007, enero-junio). Los juzgados administrativos. ¿Son la solución a la congestión de la jurisdicción?. Prolegómenos. Derechos y Valores, 163-178.

García-Pelayo, M. (1974). Burocracia y tecnocracia y otros escritos. Madrid: Alianza Universidad.

García, V. M. (2010). Los abogados en Colombia. Bogotá: Universidad Nacional de Colombia

Gell, A. (1998). Art and Agency: a New anthropological theory. Oxford: Oxford University Press.

Gómez C. (2000). Teoría general del proceso. México: Editorial Oxford.

Gupta, A. (2006). Blurred Boundaries: The Discourse of Corruption, the Culture of Politics, and the Imagined State. En Aharma, A. y Guptapor, A. (Eds.), The anthropology of the state (pp. 211-242). India: Blackwell Publishing Ltd.

Gupta, A. (2012). Red tape: Bureaucracy, structural violence an poverty in India. USA: Duke University Press.

Hull, M. (2003). The file: agency, authority, and autography in an Islamabad bureaucracy. Language \& Communication, 23, 287-314.

Hull, M. (2012a). Documents and Bureaucracy. Annual Review of Anthropology, 41, 251-267. 
Hull, M. (2012b). Government of paper: the materiality of bureaucracy in Pakistan. Los Angeles: University of California Press.

Kopitoff, I. (1991). La biografia social de las cosas: La mercantilización como proceso. En A. Appadurai, La vida social de las cosas (pp. 89-124). Mexico: Editorial Grijalbo.

Latour, B. (2010). The Making of Law: An Ethnography of the Conseil d'Etat. UK: Polity Press.

Lynch, D. (1981). Legal Roles in Colombia. Sweden: Uppsala.

Mack, K. y Anleu, S. (2012). In-court judicial behaviours , gender and legitimacy. Griffith Law Review, 21(3), 728-751.

Moreno, L. A. (2009, julio-diciembre). Reflexiones sobre la creciente congestión de la administración de la justicia en matería civil para el caso. Prolegómenos. Derechos y Valores, 213-228.

Navaro-Yashin, Y. (2007). Make-believe papers, legal forms and the counterfeit: affective interactions between documents and people in Britain and Cyprus. Anthropol. Theory 7(1), 79-98.

Noticiero oficial (2013). Diccionario jurídico. Recuperado de http://nebulosa. icesi.edu.co:2075/

Olano H. (2004). Mil juristas: Biografías de los miembros de la Academia Colombiana de Jurisprudencia 1894-2004. Bogotá: Academia

Ospina, R. (2006, julio-diciembre). Principales causas de la morosidad en la jurisdicción laboral. Prolegómenos. Derechos y Valores, 305-313.

Reed, A. (2007). 'Smuk is king': the action of cigarettes in a Papua New Guinea Prison. En Thinking through things: Theorising artefacts ethnographically (pp. 32-46). UK: Routledge. 
Silva, G. (2001). El mundo real de los abogados y de la justicia v.2: las prácticas jurídicas. Bogotá: Universidad Externado de Colombia.

Telley, C., Webb, K., Küchiler, S., Rowlands, M. y Spyer, P. (2006). Handbook of material culture. London: Sage publications,.

Uprimny, R., Rodríguez, C. y García (2003). Entre el protagonismo y la rutina: Análisis sociojurídico de la justicia en Colombia. En Fix-Fierro, H., Lawrence, M., Friedman y Pérez R. (Eds.). Culturas juridicas latinas de Europa y América en tiempos de globalización (pp. 231-304). México: Universidad Nacional Autónoma de México, Instituto de Investigaciones Jurídicas.

Visman, C. (2008). Files: Law and Media Technology. Stanford, CA: Stanford University Press.

\section{Cómo citar este artículo}

Abello, C. J. (2016). Forma y fondo: una etnografia de la materialidad de la justicia en Cali. Universitas Humanistica, 82, 335-363. http://dx.doi. org/10.11144/Javeriana.uh82.ffem 